\title{
Traumatological Application of 3D Model in Complex Acetabular Fractures
}

\author{
Battiato $C^{1}$, Basiglini $L^{1 *}$ and Giovannini $F^{2}$ \\ ${ }^{1}$ Department of Orthopedics and Traumatology, Mazzoni Hospital, Italy \\ ${ }^{2}$ Clinica Ortopedica, UNIVPM, Ancona, Italy
}

*Corresponding author: Basiglini L, Department of Orthopedics and Traumatology, Mazzoni Hospital, Italy, E-mail: Iucabasiglini@gmail.com

\begin{abstract}
Three-dimensional reconstruction (3D) and rapid prototyping (RPT), starting from computed tomographic (CT) examinations, is a promising technology in traumatology. It facilitates the planning and surgical results of complex fractures. Here, we used it in a complex bilateral acetabulum fracture for the assessment of the injury type and for improving knowledge of the fracture fragments. The patient was a forty-five-year-old male, with no accompanying fractures. The solid model allowed an accurate preoperative and intraoperative planning. The 3D printed model improved the understanding of anatomy of the fractures, in order to facilitate the surgical approach and the creation of dedicated pre-shaped plates. The use of the 3D model reduced surgical time, intraoperative soft tissues damage and blood loss as well as the risk of infections. Fluoro scoping imaging was also minimized. This case highlights the importance of $3 \mathrm{D}$ model in the management of complex fractures.
\end{abstract}

\section{Keywords}

Trauma, Innovations in traumatology, Rapid prototyping, Pelvis

\section{Introduction}

In traumatology a promising technology is three-dimensional reconstruction (3D) and rapid prototyping (RPT), starting from computed tomographic (CT) examinations. It facilitates the surgical assessment of several surgical disciplines [1-7]. The surgeon can appreciate in a realistic way details such as joint fragmentation, yielding, and dislocation of the articular surface. The simulation of the operative planning with 3D printed model offers an excellent opportunity to refine the surgical planning. Also the 3D model can be shown to the patient to improve his comprehension of the fractures and refining the consent [4-7].
We show our experience with 3D printing on two complex fractures of both acetabula present on the same patient (fracture patterns: two columns on the left and a T-shaped on the right). Surgery was performed in a single operative session with the continued comparison of the sterilized 3D model. The 3D-printed model allowed a faster and accurate understanding of the morphology of the fracture and a more accuratepreoperative planning. In this case, surgeons simulated the operative planning (i.e. fracture reduction, screw measurement, and plate positioning). This simulation allowed the modelling of plates before surgery, thus reducing both the operating time and fluoroscopic imaging.

\section{Case Report}

In July 2015 a forty-five-year-old male patient presented to our trauma centre for a complex bilateral acetabular fracture (Figure 1) after a car accident. The patient did not present accompanying fractures or bleedings and was hemodynamically stable. At the time of presentation, CT scans were taken with conventional 16-detector CT scanners with slice thickness of 0.625 $\mathrm{mm}$. The DICOM imaging files were converted in the software Mimics (Metarialise, Leuven, Belgium) by acquisition of three 2D plans (axial, coronal, sagittal) and one 3D view. 2D CT slices have a white/black appearance referring to the density of the material. Mimics is able to isolate a particular type of material starting from a selected colour (this type of process is called thresholding). Once the material has been selected, it can be transformed into a 3D image, then the file can

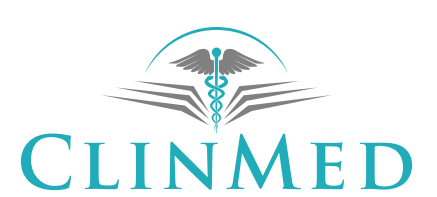

INTERNATIONAL LIBRARY
Citation: Battiato C, Basiglini L, Giovannini F (2017) Traumatological Application of 3D Model in Complex Acetabular Fractures. Trauma Cases Rev 3:053. doi.org/10.23937/2469-5777/1510053 Received: January 22, 2017; Accepted: April 11, 2017: Published: April 14, 2017

Copyright: (C) 2017 Battiato C, et al. This is an open-access article distributed under the terms of the Creative Commons Attribution License, which permits unrestricted use, distribution, and reproduction in any medium, provided the original author and source are credited. 


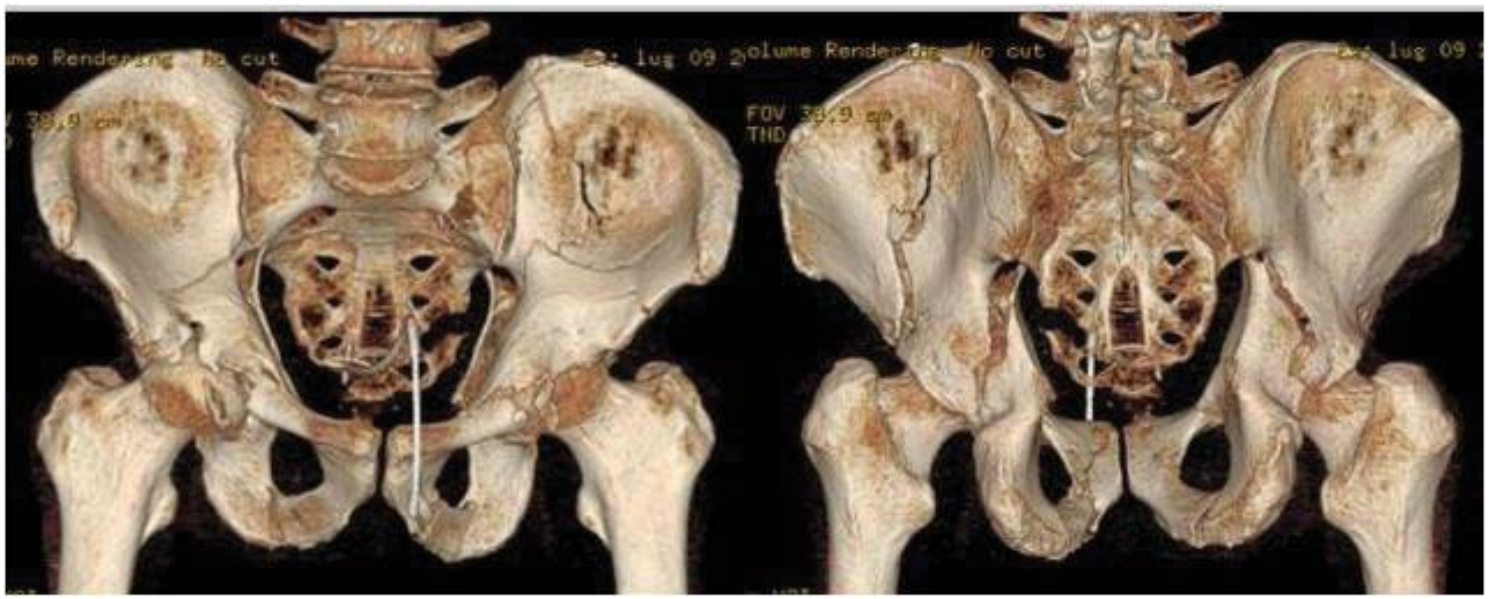

Figure 1: $3 \mathrm{~d}$ view of ct images showing a complex fracture of both the acetabula (a two columns pattern on the left acetabulum and a t-shaped fracture on the right acetabulum).

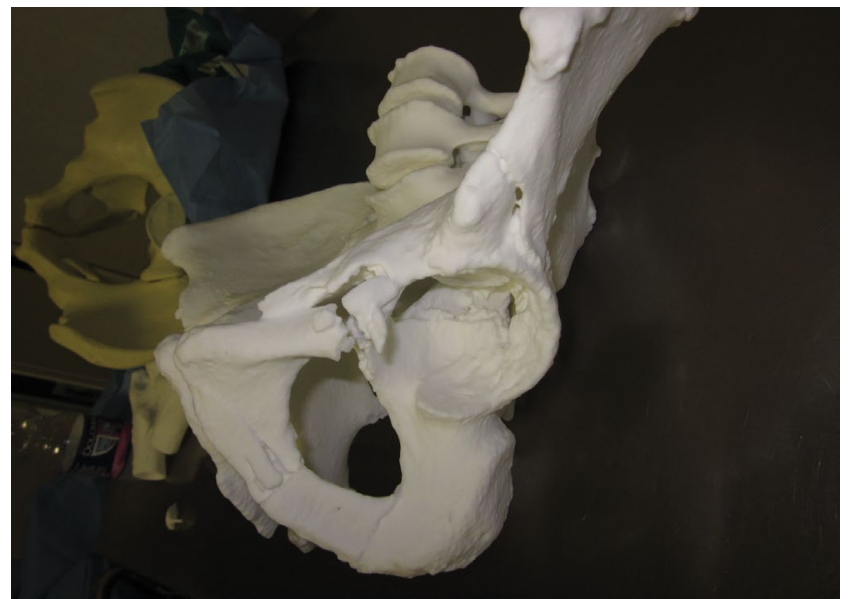

Figure 2: 3D-printed model showing a complex fracture of both the acetabula (a two columns pattern on the left acetabulum and a T-shaped fracture on the right acetabulum).

be exported. The exported file is in STL format (Standard Triangulation Language). It is used and worked for the design (CAD) and then for the rapid prototyping. Production machines using laser sintering additive, in medical Sintac offers both titanium Ti64 and polyamide. The 3D model we used here was made of polyamide PA 2200 , a polymer able to support high thermal or mechanical stresses.

\section{Preoperative application of the solid model}

The patient presented a complex fracture of both the acetabula (a 2 columns pattern on the left and a T-shaped fracture on the right acetabulum) due to a major trauma (car accident). Fortunately for the patient, he reported no other fractures or bleedings and he was hemodynamically stable. The time necessary to make the 3D model was 46 hours, starting from the $C T$ images and $3 \mathrm{D}$ reconstructions (Figure 1 and Figure 2). The Senior Surgeon (C.B.) examined the images and the 3D printed model and he performed a simulation of the operative procedures. During the simulation the Senior Surgeon pre-shaped plates (Figure 3).

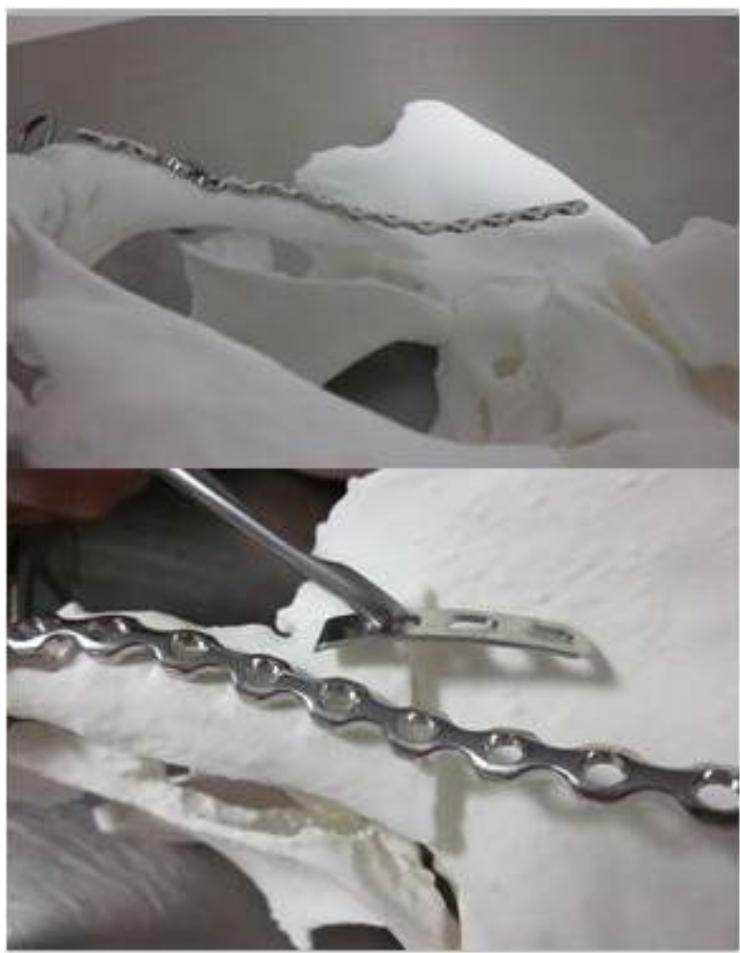

Figure 3: Preoperative simulation using the 3D printed model and pre contouring plates.

\section{Intraoperative application of the solid model}

The surgery was performed using a bilateral ileo-inguinal approach [8] with a single skin incision. The patient was supine on a radiolucent table. Surgery started from reduction of the anterior column by reduction and fixation of the iliac wing and restoring the iliac fossa concavity. Then, reduction and fixation of the posterior column and the low anterior column was performed, according to teaching of Letournel and Judet [8]. The solid model allowed an accurate preoperative and intraoperative planning (Figure 3, Figure 4 and Figure 5), mainly due to the creation of dedicated precontoured plates. The Senior Surgeon could decide length and curvature of the plates according to the 3D printed model (Figure 3, Figure 4 and Figure 5). The surgery was per- 


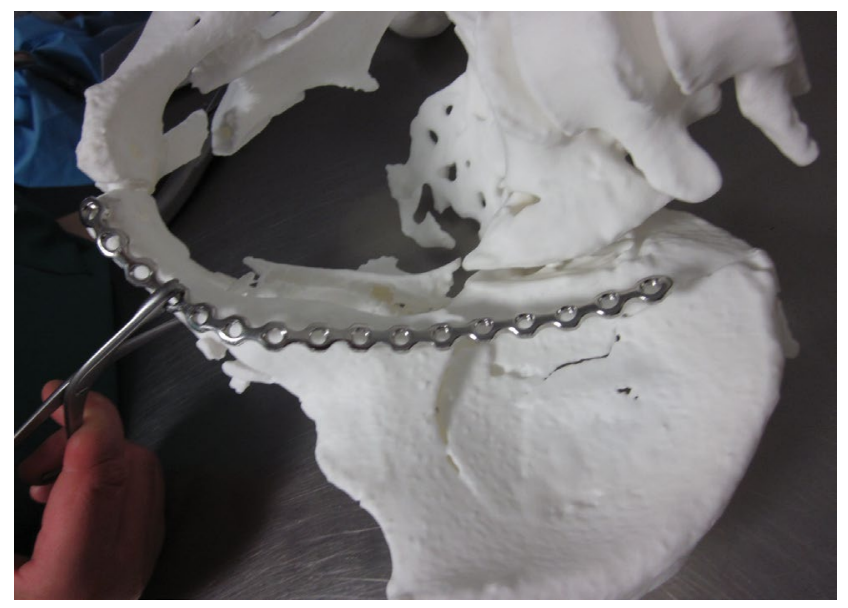

Figure 4: Preoperative simulation using the 3D printed model and pre contouring plates for the left side.

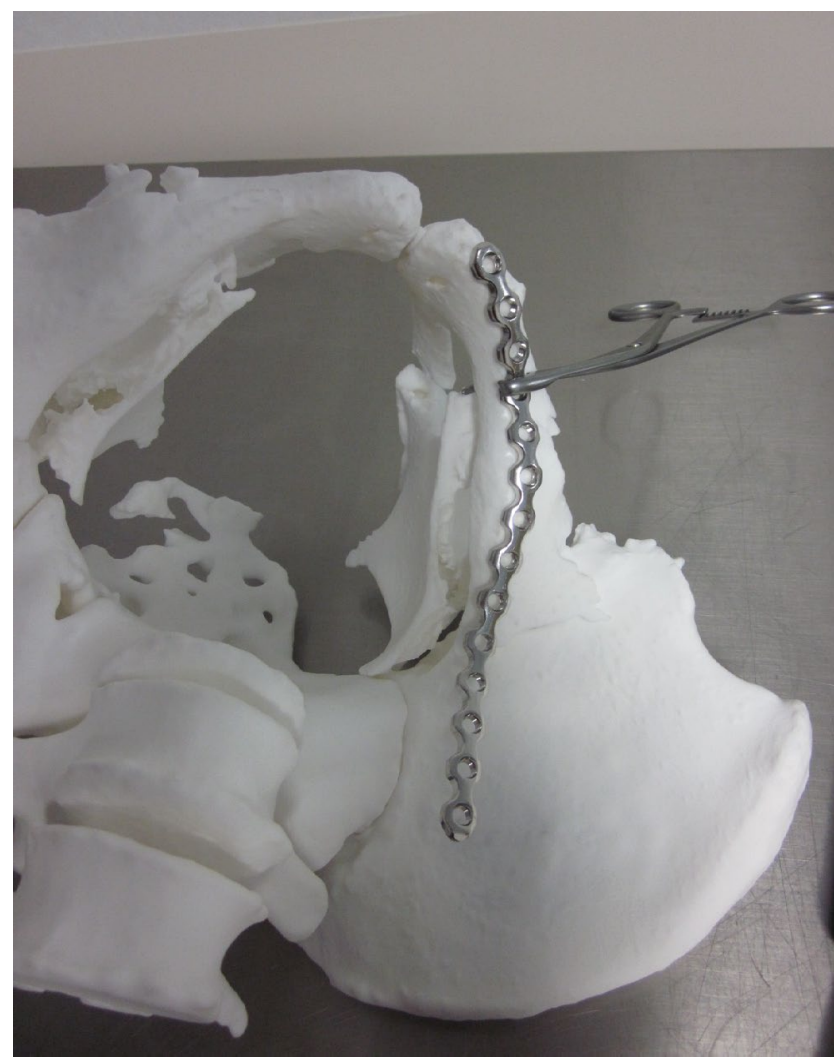

Figure 5: Preoperative simulation using the 3D printed model and pre contouring plates for the right side.

formed by checking anytime the position by palpating the pelvic model and the fracture (Figure 3, Figure 4, Figure 5 and Figure 6). The presence of the 3D model on the surgical field has increased sensitivity and specificity of the "third eye" (i.e. the digital fingering).

The possibility of learning the manoeuvres of reduction on the 3D model allowed a correct and ergonomic planning of intervention and reduced the duration of surgery. Fluoroscopic views were reduced (1 minute). The entire procedure took 205 minutes, with a blood loss of $500 \mathrm{ml}$. In our structure, a similar surgery without the 3D printed model would requires an average of 250 minutes of operating time, 2 minutes of fluorosco-

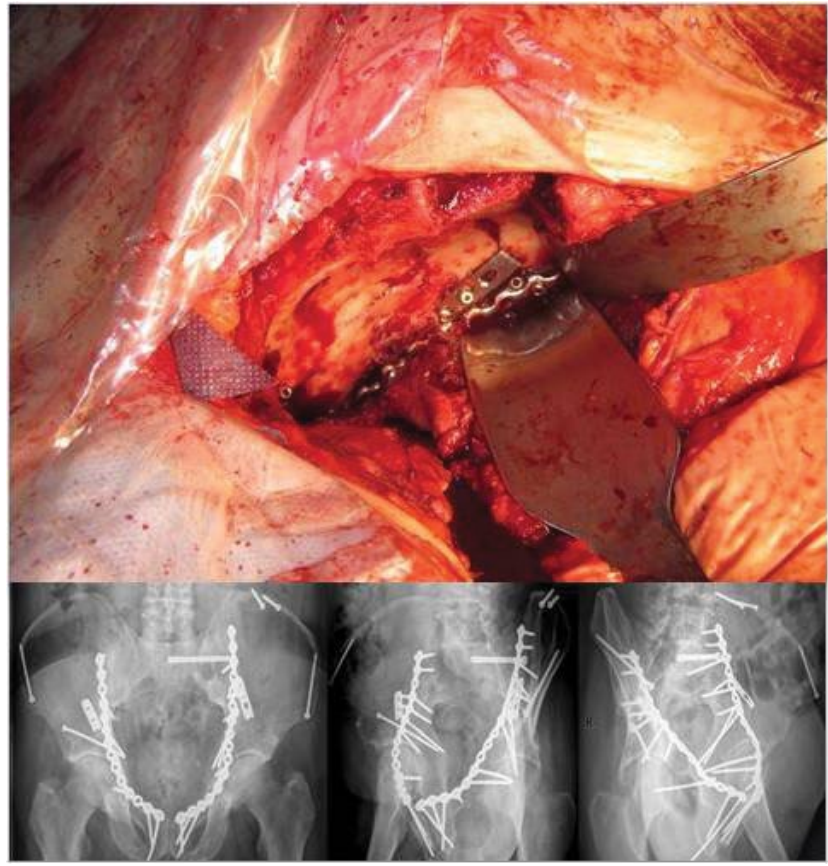

Figure 6: Intraoperative session and radiographical result at 16 months of follow-up.

py, and a blood loss of $1000 \mathrm{ml}$.

\section{Postoperative evaluation}

At the time of writing the patient is at 16 months of follow-up. The radio graphical result is excellent (Figure 6), and the patient can perform activities of daily living without experiencing discomfort or pain. The Harris Hip Score is 96.

\section{Discussion}

The use of 3D models in traumatology is at an early stage. However, clinical studies already suggest this new technology as a promising and useful option in the future [1-7,9-13]. Benefits of 3D models include reduced surgical time, decreased amount of blood loss, risk of infections and exposure to ionizing radiations. According to our experience, we think it is better to limit this technique to the treatment of complex fractures. Its application for simple fractures would bring no additional benefit except the education of younger surgeons. It is therefore more reasonable to wait for a larger commercialization of 3D models before using them for simple procedures.

\section{References}

1. Bagaria V, Deshpande S, Rasalkar DD, Kuthe A, Paunipagar BK, et al. (2011) Use of rapid prototyping and three-dimensional reconstruction modeling in the management of complex fractures. Eur J Radiol 80: 814-820.

2. Philippe B (2013) Custom-made prefabricated titanium miniplates in le Fort I osteotomies: principles, procedure and clinical insights. Int J Oral Maxillofac Surg 42: 1001-1006.

3. Yu AW, Duncan JM, Daurka JS, Lewis A, Cobb J, et al. (2015) A Feasibility Study into the Use of Three-Dimensional Printer Modelling in Acetabular Fracture Surgery. Adv Orthop. 
4. Bizzotto N, Sandri A, Regis D, Romani D, Tami I, et al. (2015) Three-Dimansional Printing of Bone Fractures: A New Tangible Realistic Way for Preoperative Planning and Education. Surg Innov 22: 548-551.

5. Brown GA, Firoozbakhsh K, DeCoster TA, Reyna JR Jr, Moneim $M$, et al. (2003) Rapid prototyping: the future of trauma surgery? J Bone Joint Surg Am 85: 49-55.

6. Bortolotto C, Eshja E, Peroni C, Orlandi MA, Bizzotto N, et al. (2016) 3D Printing of CT Dataset: Validation of an Open Source and Consumer-Available Workflow. J Digit Imaging 29: $14-21$.

7. Bizzotto N, Tami I, Tami A, Spiegel A, Romani D, et al. (2016) 3D Printed models of distal radius fractures. Injury 47: 976978.

8. Letournel E, Judet R (1993) Fractures of the Acetabulum. ( $2^{\text {nd }}$ edn), Springer, USA.
9. Markillie $P(2012)$ A third industrial revolution. The Economist Special Report 2012: 3-18.

10. Krishnan SP, Dawood A, Richards R, Henckel J, Hart AJ, et al. (2012) A review of rapid prototyped surgical guides for patient-specific total knee replacement. J Bone Joint Surg $\mathrm{Br}$ 94: 1457-1461.

11. Garrett J, Halvorson J, Carroll E, Webb LX (2012) Value of 3-D CT in classifying acetabular fractures during orthopedic residency training. Orthopedics 35: 615-620.

12. Giannoudis PV, Grotz MR, Papakostidis C, Dinopoulos H (2005) Operative treatment of displaced fractures of the acetabulum. A meta-analysis. J Bone Joint Surg Br 87: 2-9.

13. Giannetti S, Bizzotto N, Stancati A, Santucci A (2016) Minimally invasive fixation in tibial plateau fractures using an pre-operative and intra-operative real size 3D printing. Injury 48: 784-788. 